\title{
Indiscriminate mass surveillance and the public sphere
}

\author{
Titus Stahl ${ }^{1}$ D
}

Published online: 16 March 2016

(c) The Author(s) 2016. This article is published with open access at Springerlink.com

\begin{abstract}
Recent disclosures suggest that many governments apply indiscriminate mass surveillance technologies that allow them to capture and store a massive amount of communications data belonging to citizens and non-citizens alike. This article argues that traditional liberal critiques of government surveillance that center on an individual right to privacy cannot completely capture the harm that is caused by such surveillance because they ignore its distinctive political dimension. As a complement to standard liberal approaches to privacy, the article develops a critique of surveillance that focuses on the question of political power in the public sphere.
\end{abstract}

Keywords Surveillance $\cdot$ Privacy $\cdot$ Public sphere · Political power

\section{Introduction}

The liberal debate about a "right to privacy" traditionally took a certain technological background for granted. It always envisaged violations of privacy in relation to specific information about specific individuals. As a result, liberal authors often understood the right to privacy as an individual right that protects individual interests (Parent 1983; Prosser 1960; Regan 1995, p. xiii; Thomson 1975; Warren and Brandeis 1890).

It is apparent that this is problematic if one considers only one of the government programs unveiled by NSA

Titus Stahl

titus.stahl@rug.nl

1 Faculty of Philosophy, Rijksuniversiteit Groningen, Oude Boteringestraat 52, 9712 GL Groningen, The Netherlands whistle-blower Edward Snowden. As part of its TEMPORA program, the British GCHQ accesses fiber-optic cables that carry a massive amount of Internet traffic. GCHQ stores all data that passes through these cables for several days (GCHQ Authors 2014; MacAskill et al. 2013). Following analysis, subsets are selected for longer (potentially indefinite) storage. Such a program is only possible thanks to technological advances, among them price decreases for storage media and faster processors in communications equipment. The usefulness of such a program is also tied to advances in "big data" analytics, that is, search algorithms that make it possible to perform relatively quick analyses of large amounts of data (Lyon 2014).

These indiscriminate mass surveillance technologies raise several issues that are absent from classic discussions of privacy. First, they have unprecedented scale: programs like TEMPORA affect almost every member of the electorate in the concerned countries, rather than only specific individuals. While traditional discussions of privacy focus on individuals, it does not seem unreasonable to think that differences in scale also make a moral difference. It might be morally unproblematic to collect some information about a few people, but problematic to gather it for everyone all the time. A second problem concerns the separation between two senses of surveillance, surveillance in the sense of information capture and storage and in the sense of access to information (Solove 2006, p. 490). Indiscriminate surveillance technologies allow intelligence services to acquire large amounts of information first and filter out irrelevant information later. This raises the issue of whether there is something already wrong with mere information capture even when the government is legally constrained from using the information in illegitimate ways. Finally, programs like TEMPORA lead to a situation where the government regularly intercepts political 
communications between citizens. While traditional accounts of privacy typically do not focus on behavior that is intended to be public by definition (such as political speech or demonstrations), many commentators believe that political surveillance is particularly problematic (Greenwald and Hussain 2014; Wolf 2012). This special status of public, political communications is not widely acknowledged by standard liberal theories of privacy. ${ }^{1}$

Theories of privacy in the liberal tradition usually depart from one of two normative intuitions: liberal individualist and neo-republican accounts take surveillance to be a violation of individual liberty. Relational accounts take surveillance to be a violation of the individual's autonomy over his or her social relationships. This article argues that both accounts do not allow us to fully appreciate the normative issues raised by ubiquitous surveillance. First, they have difficulty making sense of the intuition that surveillance is wrong even when the information captured is not used illegitimately. Second, most liberal accounts understand the harm caused by surveillance as a threat to the individual liberty to retreat from the public sphere (Emerson 1970, p. 549). This "privative conception of privacy" has little room for reflection on how surveillance also harms collective goods. Even those authors who acknowledge the necessity of privacy for political freedom merely see privacy from public scrutiny as a precondition for political freedom, rather than privacy as an integral part of the political domain (Arendt 1958, p. 70; Cohen 2000, p. 1425; Hughes 2015; Nissenbaum 2004, p. 132; Roberts 2014; Solove 2006, p. 551). Third, the liberal view seems to counter-intuitively entail that surveillance of public (e.g. political) behavior is not particularly problematic as long as the information gathered is not used to interfere with individual liberty (Nissenbaum 2004, p. 116).

Liberal privacy theory therefore needs to be supplemented with an analysis of surveillance as the exercise of a distinctive kind of government power over the public.

\section{Mass surveillance and individual liberty}

Liberal accounts of privacy traditionally focus on the contribution of (informational) privacy to individual freedom (Roessler 2004; Solove 2006). In this context, "privacy" refers to the individual's right to exclude others (such as the government) from access to certain kinds of information. It thus delineates a protected sphere of liberty that liberal theorists take as central to the individual's

\footnotetext{
1 Surprisingly, the US legal framework incorporates stronger constraints in the case of political surveillance (due to the First Amendments) than traditional privacy theories would usually recommend (Fisher 2004).
}

ability to live an autonomous life. There are two possible arguments for such a "protective" account, referring either to the value of "negative liberty" or to the neo-republican value of "non-domination".

The first argument states that there is a necessary connection between privacy and individual "negative" liberty. We often need to keep information secret from other people to keep them from interfering with our choices (de Bruin 2010, p. 513f), to retain control over our self-presentation (Marmor 2015, p. 10) or to retain control over the access we grant others to our lives (Roessler 2004).

Privacy rights can indeed help to protect our negative liberty by keeping information out of the hands of others who would otherwise use it to interfere with our choices or our self-presentation or who would use it to gain access into previously hidden aspects of our lives. However, this argument not only fails to establish protections for political communication between citizens in public. When the issue at question is the indiscriminate gathering of information by an appropriately constrained liberal regime, this argument also does not show that there is anything intrinsically wrong about such surveillance in general. If there are legal provisions that bar the government from accessing data for purposes of interfering illegitimately with people's choices, no degree of surveillance will decrease their negative liberty in the sense of non-interference. One might argue that surveillance constitutes an infringement of negative liberty in the sense of control over access, as by definition surveillance implies that those affected have no choice about whether they want the government to have access to the relevant information. However, in the case of an appropriately constrained government, no additional choices seem to be affected, such that the impact on their liberty seems to remain marginal.

Of course, these arguments presuppose that the government indeed resists the temptation to interfere illegitimately, a premise that is doubted by many (Stallman 2013). However, we not only make this assumption in other regards for democratic governments. This argument also makes it obvious that the main worry on this account is not surveillance, but interference. If indiscriminate mass surveillance does not lead to an increase in government interference, a negative liberty account must remain neutral towards such developments.

A second argument is presented by neo-republican authors. According to these authors, what privacy protects us from is not interference but domination. Someone is dominated whenever there is someone else who has the option of arbitrarily interfering with their choices, whether this option is taken or not (Lovett 2010; Pettit 1997). Therefore, it does not matter that the information that is gathered by indiscriminate mass surveillance is, in fact, not abused (Skinner 2015). The mere fact that surveillance puts 
the government in a position to use it to interfere with its citizens' choices constitutes domination (Roberts 2014). Such an account seems to be better suited for a critique of indiscriminate mass surveillance because it entails that the fact that surveillance creates or increases the power of the state to interfere constitutes domination.

This neo-republican argument can explain why information gathering (enabling the potential use of information) is possibly harmful. However, surveillance as such is certainly never sufficient to ensure that some agent is in a position to interfere with my choices. Even when an agent succeeds, through surveillance, in acquiring all the information necessary to interfere with me, there are almost always other means available to third parties to block such an agent from actually interfering. In the case of the government, the most obvious choice for providing such means is a strong constitutional rights regime.

It follows that indiscriminate mass surveillance is not intrinsically wrong, but it can contribute to domination when there are no other rules or constraints that block arbitrary interference. However, if such further restraints are missing, it is the fact that they are absent that leads to domination, not the mere possibility of surveillance in isolation. Just like the negative liberty argument, the neorepublican argument does not account for the widespread intuition that there is something intrinsically wrong with indiscriminate mass surveillance (Hoye and Monaghan 2015)

\section{Relational accounts}

Liberal individualist and neo-republican accounts understand privacy only as valuable insofar as it protects individual liberty. Therefore, the social and political effects of surveillance often escape their notice. This individualist bias has often been criticized by communitarian and feminist theorists (Etzioni 2000; MacKinnon 1987, p. 96). Within the liberal tradition, as well, many authors have recognized that a purely individualist defense of a right to privacy is problematic (Regan 1995, p. xiv). In response to these worries, it is sometimes argued that privacy not protects individual freedom of action but that it also safeguards certain forms of social interaction (Fried 1968; Rachels 1975; Schoeman 1984; Solove 2007) Therefore, many authors hold that privacy is both valuable for the individual and for society (Hughes 2015). While the social value of privacy is often only acknowledged in terms of privacy enabling intimate relationships (Inness 1992), some authors have recently also emphasized its value for non-intimate relationships (Roessler and Mokrosinska 2013, p. 772). Intimate as well as professional relationships are governed by conventional norms that either mandate or prohibit sharing certain information. For example, many kinds of intimate relationships are governed by a norm mandating that one must exclusively share certain kinds of personal information. Relationships between lecturers and students, in contrast, are governed by a norm mandating that lecturers must not share certain details about their private life with students (Roessler and Mokrosinska 2013, p. 781). In both cases, it is control over information sharing that enables people to engage in different roles (Roessler 2004, p. 131; Westin 1970, p. 7). Something similar is even true for relationships between strangers in public: the "civil inattention" that members of the public expect from each other enables them to interact with each other as citizens (Nagel 1998; Nissenbaum 1997; Roessler and Mokrosinska 2013, p. 782; Solove 2007, p. 762).

While these arguments acknowledge the social value of privacy and show that privacy rights can also protect public activities, it is not entirely clear what they entail for the issue of indiscriminate mass surveillance. First, most intimate and professional relationships are not, in fact, undermined by mass surveillance. People have successful, intimate long-distance relationships, communicating over channels that they know are subject to government monitoring. Second, these theories spell out the non-intimate value of privacy in public by reference to the practice of "civil inattention" between citizens. However, as long as governments only collect and store communications and do not disclose them to third parties, this does not seem to undermine this practice. Third, the value of privacy in these respects still mainly refers to control over information that people are assumed to want to keep secret from others (such as intimate details about their life). If the information that is collected concerns citizens' political activities, this seems not to undermine privacy in this role-functional sense.

\section{Political power}

In order to develop an alternative account that avoids these problems, I will now argue that indiscriminate mass surveillance amounts to a distinctive form of the exercise of political power over the public sphere. In the final section of the paper, I will attempt to show-based on Jürgen Habermas's theory of the public sphere-that surveillance violates a basic interest of a democratic public to exercise control over its collective practices. With this argument, I want to provide a more substantial foundation for the idea that privacy is a political value (Goold 2009, 2010; Regan 1995, p. 225ff; Simitis 1987).

For the purpose of this argument, it is worth taking a brief look at the concept of power more generally: power is usually taken as the ability of an agent to control the 
behavior of another agent (Dahl 2002; Wartenberg 1991; Weber 1978). Most familiar cases of power concern the ability of agents either to physically control the behavior of other agents or to provide them with reasons to perform certain actions, for example, by issuing threats or offering incentives. Consequently, we typically think of political power as the government's power to coercively enforce rules that set up a structure of sanctions and incentives (Luhmann 1979).

However, if we understand power as the ability to influence the behavior of others by means of influencing their reasons, we can see that political power can also have other modalities. Many of the reasons that govern people's actions are not independent of social institutions. For example, if one performs an action out of professional obligation, patriotic duty or romantic commitment, the reasons involved in these acts presuppose certain social institutions and shared understandings. The reasons that govern social interactions, in particular, are very often dependent on the participants standing in specific social relationships with each other and having certain social roles (Hayward 2000; Isaac 1987; Wartenberg 1991). One can therefore exercise power over people not only by directly giving them reasons to act (such as by providing an incentive) but also indirectly by influencing the social "space of reasons" that is available to them (Forst 2015, p. 14), for example, by making certain kinds of relationships difficult to obtain, de facto unavoidable or obligatory. The political power of governments typically includes this capacity. Through legislation and executive actions, governments can change the social context of citizens' interactions, creating or changing non-government institutions in ways that change the space of reasoning that is available for their members.

New technologies of indiscriminate mass surveillance have made new forms of such "indirect", reasons-based power available to governments. These technologies allow them to shape the communicative environment of citizento-citizen communications, such that certain kinds of relationships become impossible and others become unavailable. Such technologies shape the public sphere in a way that is likely to have an effect on those reasons that are dependent on the citizens standing in certain kinds of relationships in the public sphere.

For example, imagine an activist group that deliberates about how best to address the public. Such a group might not need to keep any information secret from the government. Nevertheless, it might be essential for the social relationships sustaining the concrete processes of deliberation within this group that no one else is involved in some discussions-not even the government in a listening capacity (Fisher 2004, p. 646; Starr et al. 2008; Tilly 2005). Similarly, the practice of "consciousness raising" is a central element of feminist activism (MacKinnon 1989, Chap. 5). It is fundamental to this practice that it is a matter of women talking to each other, without men being involved. The reason for this is not that the women engaging in this practice want to keep information secret, but because the absence of men allows them to engage in certain relationships with each other that, again, sustain a distinctive form of political deliberation. We can only make sense of such practices when we acknowledge that the collective ability of a group to control who participates in a given social context amounts to control over the form of relationships that become possible in that context and that such control sustains practices and forms of reasoning that are essential for political agency in the public sphere.

It is important to note that we can only understand why the mere surveillance of groups can constitute a form of power when we recognize the link between control over membership in groups, the structure of social relationships between members, and the reasons that emerge from such relationships. If communications in the public sphere are subject to surveillance, most members of the public lose the ability to control their social relationships to other members leading to a change of the character of the relationships constitutive of the public sphere. As a consequence, if a government engages in indiscriminate surveillance, then it exercises political power by shaping the space of agency that social roles make available to citizens and thereby the reasons that can potentially lead them to action.

\section{Surveillance and the value of the public sphere}

Having argued that surveillance is a form of relationshipshaping political power, I will now turn to the issue of the legitimacy of such power: should the state exercise such power and what should be its limits?

Initially, it might seem as if we could easily solve this question with another variation of the liberal account, arguing that surveillance violates the citizens' right to determine who has access to the groups that are important to them. However, it is quite obvious that, if there is such a right, it cannot be an individual right-individuals typically do not have the right to determine who can be a member of the various groups they move in. What mass surveillance constrains is therefore not individual liberty but collective self-determination.

Furthermore, even if one admits that indiscriminate mass surveillance amounts to an exercise of political power over some part of the public sphere, why should this be considered problematic? Certainly, not all potential forms of collective self-determination are intrinsically valuable, and not all relationships and all reasons they give rise to are 
equally worthy of protection. In other words, the argument as it has been developed so far does not tell us anything about the proper limits of government surveillance.

In order to answer these questions, one has to look more closely at the specific value of a political public sphere. In the liberal tradition, authors like John Stuart Mill (1989) have emphasized the value of the public sphere for individual freedom, referring to the epistemic benefits of public discussion in terms of an increased chance to arrive at the truth and in terms of the intrinsic value of having a public sphere in which people can realize their individuality by taking up positions towards important issues (Cohen 2000, p. 1426; Regan 1995 , p. 222). These arguments lead Mill to a principle that recommends that the government should only minimally interfere in the public sphere because all interventions by non-discursive means tend to undermine these benefits (although there are also always reasons that can justify such intrusions). This argument can easily be extended from censorship to surveillance as soon as it is acknowledged that surveillance is also a form of the government intervening in the public sphere.

Such an argument is still relatively weak, however, as it does not establish a special status for political communications. More importantly, it is open to the objection, once more, that the mere gathering and storage of information does not typically lead to any harm in these regards.

A stronger foundation for a critique of indiscriminate mass surveillance of public political activities can be found in Habermas's theory of the public sphere (Habermas 1991, 1996). Habermas describes the public sphere as a collection of practices that regulate themselves on the basis of norms that aim at generating consensus through argumentative agreement rather than through strategic threats and sanctions. Communicative interaction in the public sphere is thus distinct from action coordination in the sphere of the state where bureaucratic power is the regulating medium (and from the market, where that function is performed by money). By arguing that such interaction enables the development of "communicative rationality", Habermas not only emphasizes that the public sphere incorporates a specific form of social interaction, but also that this type of interaction underpins a specific form of rationality-not the means-ends rationality of government and the market, but a specific discursive form of rationality through which arguments, goals, and values themselves can be examined. The public sphere can only display this specific form of rationality under certain conditions, however: people must not only be capable of communicating without outside intervention distorting the internal logic of discourse (Parsons 2015, p. 8), they must also be capable of determining the structure and the rules of their communicative interactions themselves using communicative reason (Cohen and Arato 1997; Habermas 1996, p. 370). What counts as a good argument and which forms of discourse are sufficient to settle specific matters must be something that is up to the participants themselves in such communicative interactions.

If we combine Habermas's account of the public sphere with his idea that a well-functioning political public sphere is the only source of democratic legitimation, this provides us not only with an argument for why the political public sphere specifically deserves protection from state intervention. Connecting his account with the idea that surveillance shapes relationships and thereby reasons inevitably leads to the conclusion that surveillance of the public sphere undermines the specific form of rationality that this sphere displays in the ideal case. This is because surveillance makes it impossible for participants to control the relationships that are constitutive of specific forms of discourses. Therefore, surveillance must count as an intervention into the process of collective reasoning distinctive to this sphere.

Feminist critics of Habermas, such as Fraser (1990), have extended his conception arguing that subordinated groups often need public spheres of their own to effectively participate in politics. They consequently argue that political legitimacy must be based on the interaction of multiple publics, each of them controlled by members of the relevant groups. Following these arguments, it seems reasonable to conclude that autonomous collective control over the relationships constituting not only one but multiple public spheres is a precondition for the participation of both the majority and minorities in democratic selfgovernment.

This argument leads to a new account of the harm created by surveillance: indiscriminate surveillance of political, public activities removes the option for participants of the public sphere to collectively determine what social relations are appropriate for this sphere and it thereby limits their ability to exercise collective communicative freedom (Habermas 1996, p. 369; Warner 2002). The interest that is violated by surveillance is, consequently, not only an individual interest in liberty but also a collective interest in self-determination that can only be effectively safeguarded by exempting political public spheres from surveillance (Parsons 2015).

These considerations suggest that indiscriminate mass surveillance not only threatens individual liberty and nondomination and undermines valuable non-political relationships, but that it also constitutes a form of exercise of political power over the public sphere that is incompatible with the idea of democratic self-determination.

In contrast to liberal theories, this account does not base its critique of surveillance on the value of the private sphere for individual liberty, but it also acknowledges a distinct political value of surveillance-free public 
interaction. Furthermore, it can show why not only the use but also the mere gathering of information can be problematic. This is because the gathering of information changes the environment of social relationships and thereby undermines collective self-determination.

Regarding policy considerations, this argument suggests much stronger constraints on indiscriminate mass surveillance than the liberal accounts: first, the employment of technologies of indiscriminate data capture and storage that encompass the public sphere by design, such as the British TEMPORA program, is in principle illegitimate. Second, whenever more targeted surveillance technologies of any kind are employed, there needs to be a heightened bar of review and opportunities for contestation whenever this affects the public sphere (in the widest sense of the term), even when there are no individuals whose individual liberty rights are violated. Third, the government use of surveillance technologies in the public sphere must always remain appropriately restricted so that surveillance-free spaces of public deliberation remain available that would allow for both small-scale (e.g. for activist groups) and large-scale group deliberation.

Acknowledgments I would like to thank Beate Roessler, Bernardo Caycedo, the participants of the University of Amsterdam Politics and Public Affairs colloquium and members of the audience at the Amsterdam Privacy Conference for feedback, and Jonathan Wood for help with preparing the manuscript.

Open Access This article is distributed under the terms of the Creative Commons Attribution 4.0 International License (http://crea tivecommons.org/licenses/by/4.0/), which permits unrestricted use, distribution, and reproduction in any medium, provided you give appropriate credit to the original author(s) and the source, provide a link to the Creative Commons license, and indicate if changes were made.

\section{References}

Arendt, H. (1958). The human condition. Chicago: The University of Chicago Press.

Cohen, J. E. (2000). Examined lives: Informational privacy and the subject as object. Stanford Law Review, 52(5), 1373-1438. doi: $10.2307 / 1229517$.

Cohen, J. L., \& Arato, A. (1997). Civil society and political theory. Cambridge, MA: MIT Press.

Dahl, R. A. (2002). Power. In M. Haugaard (Ed.), Power. A Reader (pp. 5-25). Manchester: Manchester University Press.

de Bruin, B. (2010). The liberal value of privacy. Law and Philosophy, 29(5), 505-534. doi:10.1007/s10982-010-9067-9.

Emerson, T. I. (1970). The system of freedom of expression. New York: Random House.

Etzioni, A. (2000). The limits of privacy. New York: Basic Books.

Fisher, L. E. (2004). Guilt by expressive association: Political profiling, surveillance and the privacy of groups. Arizona Law Review, 46, 621-675.

Forst, R. (2015). Noumenal power. Journal of Political Philosophy, 23(2), 111-127. doi:10.1111/jopp.12046.
Fraser, N. (1990). Rethinking the public sphere: A contribution to the critique of actually existing democracy. Social Text, 25, 56-80. doi: $10.2307 / 466240$.

Fried, C. (1968). Privacy. The Yale Law Journal, 77(3), 475-493. doi:10.2307/794941.

GCHQ Authors. (2014). GCHQ report on the technical abilities of TEMPORA. Electronic Frontier Foundation. https://www.eff. org/document/20140618-der-spiegel-gchq-report-technical-abil ities-tempora. (Accessed November 23, 2015).

Goold, B. J. (2009). Surveillance and the political value of privacy. Amsterdam Law Forum, 1(4), 3-6.

Goold, B. J. (2010). How much surveillance is too much? Some thoughts on surveillance, democracy, and the political value of privacy (SSRN Scholarly Paper No. ID 1876069). Rochester, NY: Social Science Research Network. http://papers.ssrn.com/ abstract $=1876069$. (Accessed November 24, 2015).

Greenwald, G., \& Hussain, M. (2014). Meet the Muslim-American leaders the FBI and NSA have been spying on. The Intercept. http://theintercept.com/2014/07/09/under-surveillance/. (Accessed November 23, 2015).

Habermas, J. (1991). The structural transformation of the public sphere: An inquiry into a category of bourgeois society. Cambridge, MA: MIT Press.

Habermas, J. (1996). Between facts and norms: Contributions to a discourse theory of law and democracy. Cambridge: Polity.

Hayward, C. R. (2000). De-facing power. Cambridge: Cambridge University Press.

Hoye, J. M., \& Monaghan, J. (2015). Surveillance, freedom and the republic. European Journal of Political Theory. doi:10.1177/ 1474885115608783.

Hughes, K. (2015). The social value of privacy, the value of privacy to society and human rights discourse. In B. Roesser \& D. Mokrosinska (Eds.), Social dimensions of privacy (pp. 225-243). Cambridge: Cambridge University Press. doi:10.1017/ CBO9781107280557.013.

Inness, J. C. (1992). Privacy, intimacy, and isolation. Oxford: Oxford University Press.

Isaac, J. C. (1987). Power and Marxist theory. A realist view. Ithaca: Cornell University Press.

Lovett, F. (2010). A general theory of domination and justice. Oxford: Oxford University Press.

Luhmann, N. (1979). Trust and power. Chichester: Wiley.

Lyon, D. (2014). Surveillance, snowden, and big data: Capacities, consequences, critique. Big Data \& Society, 1(2), 1-13. doi:10. 1177/2053951714541861.

MacAskill, E., Borger, J., Hopkins, N., Davies, N., \& Ball, J. (2013). GCHQ taps fibre-optic cables for secret access to world's communications. The Guardian. http://www.theguardian.com/ uk/2013/jun/21/gchq-cables-secret-world-communications-nsa. (Accessed November 23, 2015).

MacKinnon, C. A. (1987). Feminism unmodified: Discourses on life and law. Cambridge, MA: Harvard University Press.

MacKinnon, C. A. (1989). Toward a feminist theory of the state. Cambridge, MA: Harvard University Press.

Marmor, A. (2015). What is the right to privacy? Philosophy \& Public Affairs, 43(1), 3-26. doi:10.1111/papa.12040.

Mill, J. S. (1989). On liberty and other writings. Cambridge: Cambridge University Press.

Nagel, T. (1998). Concealment and exposure. Philosophy \& Public Affairs, 27(1), 3-30.

Nissenbaum, H. (1997). Toward an approach to privacy in public: Challenges of information technology. Ethics and Behavior, 7(3), 207-219. doi:10.1207/s15327019eb0703_3.

Nissenbaum, H. (2004). Privacy as contextual integrity. Washington Law Review, 79(1), 101-139. 
Parent, W. A. (1983). Privacy, morality, and the law. Philosophy \& Public Affairs, 12(4), 269-288.

Parsons, C. (2015). Beyond privacy: Articulating the broader harms of pervasive mass surveillance. Media and Communication, 3(3), 1-11. doi:10.17645/mac.v3i3.263.

Pettit, P. (1997). Republicanism. A theory of freedom and government. Oxford: Oxford University Press.

Prosser, W. (1960). Privacy. California Law Review, 48(3), 383-423.

Rachels, J. (1975). Why privacy is important. Philosophy \& Public Affairs, 4(4), 323-333.

Regan, P. M. (1995). Legislating privacy. Technology, social values, and public policy. Chapel Hill: University of North Carolina Press.

Roberts, A. (2014). A republican account of the value of privacy. European Journal of Political Theory. doi:10.1177/ 1474885114533262.

Roessler, B. (2004). The value of privacy. Cambridge: Polity.

Roessler, B., \& Mokrosinska, D. (2013). Privacy and social interaction. Philosophy and Social Criticism, 39(8), 771-791.

Schoeman, F. (Ed.). (1984). Privacy and intimate information. In Philosophical dimensions of privacy. Cambridge: Cambridge University Press.

Simitis, S. (1987). Reviewing privacy in an information society. University of Pennsylvania Law Review, 135(3), 707-746.

Skinner, Q. (2015). Liberty, liberalism and surveillance: A historic overview. OpenDemocracy. https://www.opendemocracy.net/ ourkingdom/quentin-skinner-richard-marshall/liberty-liberalismand-surveillance-historic-overview. (Accessed July 10, 2015).

Solove, D. J. (2006). A taxonomy of privacy. University of Pennsylvania Law Review, 154(3), 477-564. doi:10.2307/ 40041279.
Solove, D. J. (2007). 'I've got nothing to hide' and other misunderstandings of privacy. San Diego Law Review, 44, 745-772.

Stallman, R. (2013). How much surveillance can democracy withstand? GNU Project. https://www.gnu.org/philosophy/sur veillance-vs-democracy.html. (Accessed November 23, 2015).

Starr, A., Fernandez, L. A., Amster, R., Wood, L. J., \& Caro, M. J. (2008). The impacts of state surveillance on political assembly and association: A socio-legal analysis. Qualitative Sociology, 31(3), 251-270. doi:10.1007/s11133-008-9107-z.

Thomson, J. J. (1975). The right to privacy. Philosophy \& Public Affairs, 4(4), 295-314.

Tilly, C. (2005). Trust and rule. Cambridge: Cambridge University Press.

Warner, M. (2002). Publics and counterpublics. Public Culture, 14(1), $49-90$.

Warren, S. D., \& Brandeis, L. D. (1890). The right to privacy. Harvard Law Review, 4(5), 193-220. doi:10.2307/1321160.

Wartenberg, T. (1991). Forms of power: From domination to transformation. Philadelphia: Temple University Press.

Weber, M. (1978). Economy and society. In G. Roth \& C. Wittich (Eds.), Berkeley: University of California Press.

Westin, A. F. (1970). Privacy and freedom. London: The Bodley Head.

Wolf, N. (2012). Revealed: How the FBI coordinated the crackdown on occupy. The Guardian. http://www.theguardian.com/commen tisfree/2012/dec/29/fbi-coordinated-crackdown-occupy. (Accessed July 15, 2015). 